\title{
A Review of the State-of-Art, Limitations, and Perspectives of Machine Vision for Grape Ripening Estimation ${ }^{\dagger}$
}

\author{
Eleni Vrochidou* (D), Christos Bazinas (D), George A. Papakostas (D), Theodore Pachidis (D) and Vassilis G. Kaburlasos \\ Human-Machines Interaction Laboratory (HUMAIN-Lab), Department of Computer Science, International \\ Hellenic University (IHU), 65404 Kavala, Greece; chrbazi@cs.ihu.gr (C.B.); gpapak@cs.ihu.gr (G.A.P.); \\ pated@cs.ihu.gr (T.P.); vgkabs@cs.ihu.gr (V.G.K.) \\ * Correspondence: evrochid@cs.ihu.gr \\ + Presented at the 13th EFITA International Conference, online, 25-26 May 2021.
}

check for updates

Citation: Vrochidou, E.; Bazinas, C.;

Papakostas, G.A.; Pachidis, T.;

Kaburlasos, V.G. A Review of the State-of-Art, Limitations, and Perspectives of Machine Vision for Grape Ripening Estimation. Eng. Proc. 2021, 9, 2. https://doi.org/10.3390/ engproc2021009002

Academic Editors: Charisios Achillas and Lefteris Benos

Published: 19 November 2021

Publisher's Note: MDPI stays neutral with regard to jurisdictional claims in published maps and institutional affiliations.

Copyright: (c) 2021 by the authors. Licensee MDPI, Basel, Switzerland. This article is an open access article distributed under the terms and conditions of the Creative Commons Attribution (CC BY) license (https:// creativecommons.org/licenses/by/ $4.0 /)$.

\begin{abstract}
This work highlights the most recent machine vision methodologies and algorithms proposed for estimating the ripening stage of grapes. Destructive and non-destructive methods are overviewed for in-field and in-lab applications. Integration principles of innovative technologies and algorithms to agricultural agrobots, namely, Agrobots, are investigated. Critical aspects and limitations, in terms of hardware and software, are also discussed. This work is meant to be a complete guide of the state-of-the-art machine vision algorithms for grape ripening estimation, pointing out the advantages and barriers for the adaptation of machine vision towards robotic automation of the grape and wine industry.
\end{abstract}

Keywords: grape ripeness estimation; machine vision; harvesting robot; image analysis; sustainable agriculture

\section{Introduction}

Grape harvesting is a great challenge that requires cost-effective solutions. The choice of harvest time determines the quality of the yield. Especially in wine production, deciding on the optimal harvest time concerning certain compounds, such as anthocyanins, is crucial in order to obtain optimal wine quality. Additionally, different vineyards ripen at different rates. Identifying maturity zones could enhance the efficiency of the harvesting operation. Grape harvesting based on grape ripening stage estimation increases the sustainable production of grape fruit products in the following three main directions: (1) improvement of the quality of harvested grapes due to homogenously ripened and equally fresh fruit, (2) reducing the post-harvest waste along the supply chain, and (3) reducing the production costs and human labor due to sustainable resource management.

In this context, an automated approach for grape ripeness estimation is considered necessary. Research focuses on the development of non-destructive, cost-effective, and environmentally friendly techniques. Machine vision has recently gained considerable acceptance for agricultural-related tasks. To this end, machine vision has been employed in in-field practical applications for the assessment of grape ripeness. The reported results reveal that image processing has good potential to be used for grape ripeness estimation, not as a substitute, but rather as an attractive alternative to chemical analyses, due to its simplicity, flexibility, and low cost. The aim of this work is to increase the insight into the application of machine vision techniques for grape ripening estimation. The techniques reported here are recent, and could be utilized as effective and rapid tools for decision making regarding the desirable harvest time.

\section{Machine Vision Methods for Grape Ripeness Estimation}

Different grape cultivars display a different refractometric index, which is related to maturity. For instance, table grapes must have at least $16^{\circ}$ Brix to be considered ripened, 
while Sauvignon Blanc may ripen at $20-22^{\circ}$ Brix, etc. However, even this is relevant, since the proper harvesting time is not necessarily related to a standard ripening value, but to a desired ripening value depending on the harvested variety. In the wine industry, the health condition and maturity of harvested grapes need to be evaluated in order to determine the exact procedure, diffusional, enzymatic, or biochemical, to be applied. Objective criteria to judge the ripeness stage of grapes are those related to chemical attributes, such as titratable acidity (TA), soluble solid content (SSC), etc. Subjective maturation criteria are just as important, and include the sensory characteristics chosen to be discriminative among samples.

During ripening, many physical and biochemical changes occur that affect grape characteristics. Usually, red-green-blue (RGB) imaging is the most cost-effective way to determine color channel values and other characteristics, such as shape and texture. The RGB color space depends on the device on which it is displayed; therefore, it is not adequate when it comes to absolute measures. For this reason, the CIELAB color space is used as an international standard for color measurements. However, alternative color spaces have also been investigated, such as hue-saturation-intensity (HIS), hue-saturation value (HSV), etc. Classic near-infrared (NIR) spectroscopy has been proven as a powerful analytical tool to designate bioactive compounds in grapes. The main advantage of NIR spectroscopy over other methods is the chemical-free sample preparation and the ability to determine efficiently optical properties of the fruit that are strongly related to the chemical and physical properties, and, thus, to maturity. Hyperspectral imaging is also considered to be an evolving tool, since it combines conventional imaging with spectroscopy, and, thus, one can obtain both the spectral and spatial information of an object. Table 1 summarizes the recent applications of hyperspectral imaging, color imaging, and NIR spectroscopy for grape ripeness estimation.

A limitation of the use of machine vision algorithms in grape-related applications is attributed to the lack of large-scale public datasets of grape bunch images for testing innovative methodologies and performing comparative evaluation reports. Researchers must rely on the data collected by themselves, which are neither universal nor comparable. The complexity of agricultural environments in terms of diversity and dynamically changing conditions, such as illumination and vegetation, are the main obstacles that machine vision technology attempts to overcome. Robust algorithms, able to operate in heterogeneous environments, need to be developed. The application of visual technology in the field involves the integration of multiple parameters and principles that can only be encountered in natural setups, in practical applications, and not in laboratory settings. In recent years, the development of graphical peripheral units (GPUs) helped to increase the computational power and allowed powerful real-time pattern recognition techniques to be used on-site. In the future, machine vision algorithms are expected to play a vital role in sustainable agricultural automation, towards improving local economies and promoting ecology. 
Table 1. Applications of hyperspectral imaging for grape ripeness estimation.

\begin{tabular}{|c|c|c|c|c|c|c|}
\hline Cultivar & Maturity Index & $\begin{array}{l}\text { Spectral Range/ } \\
\text { Color Space }\end{array}$ & $\begin{array}{l}\text { Number of } \\
\text { Images }\end{array}$ & Prediction Model & Evaluation & Ref. \\
\hline $\begin{array}{l}\text { Touriga Franca (TF), } \\
\text { Touriga Nacional (TN), } \\
\text { Tinta Barroca (TB) }\end{array}$ & $\mathrm{pH}$, anthocyanin & $380-1028 \mathrm{~nm}$ & 225 & Neural Network (NN) & $\begin{array}{c}\text { pH R } \mathrm{R}^{2}: 0.723(\mathrm{TF}), 0.661(\mathrm{TN}), 0.710 \\
(\mathrm{~TB}) \\
\text { Anthocyanin } \mathrm{R}^{2}: 0.906(\mathrm{TF}), 0.751 \\
(\mathrm{TN}), 0.697(\mathrm{~TB})\end{array}$ & [1] \\
\hline cv. Malagousia & TSS, $\mathrm{pH}$ & $510-790 \mathrm{~nm}$ & 12 & $\begin{array}{l}\text { Multiple linear regressor (MLR), } \\
\text { support vector machine (SVM) }\end{array}$ & $\begin{array}{l}\text { Classification rates: TSS } 83.33 \% \\
\text { (MLR), TSS 83.33\% (SVM), pH 75\% } \\
\text { (MLR), pH 75\% (SVM) }\end{array}$ & [2] \\
\hline Syrah, Tempranillo & Flavanols, total phenols & $900-1700 \mathrm{~nm}$ & 200 & $\begin{array}{l}\text { principal component analysis, } \\
\text { modified partial least squares, } \\
\text { K-means, linear discriminant }\end{array}$ & $\begin{array}{c}\text { Classification rates: } 83.3 \% \\
\text { (leave-one-out cross-validation), } \\
76.9 \% \text { (external validation) }\end{array}$ & [3] \\
\hline $\begin{array}{l}\text { Vitis vinifera L. cv., } \\
\text { Tempranillo, Syrah }\end{array}$ & Anthocyanins & $900-1700 \mathrm{~nm}$ & 99 & Principal component analysis & $0.86 \mathrm{R}^{2}$ & [4] \\
\hline Kyoto grapes & $\mathrm{SSC}, \mathrm{pH}$ & $\begin{array}{l}\text { HIS, NTSC, YCbCr, HSV, } \\
\text { CMY }\end{array}$ & 180 & $\begin{array}{c}\text { Multiple linear regressor (MLR), } \\
\text { partial least-squares regressor } \\
\text { (PLSR) }\end{array}$ & $\begin{array}{c}\text { Mean square error: pH } 0.0987 \\
\text { (MLR), pH 0.1257 (PLSR), SSC } \\
0.7982 \text { (MLR), SSC } 0.9252 \text { (PLSR) }\end{array}$ & [5] \\
\hline Italia, Victoria & Visual assessment & HSV, CIELAB & 800 & Random forest (RF) & $\begin{array}{c}\text { Cross-validation classification } \\
\text { accuracy: up to } 100 \% \text { (Italia), up to } \\
0.92 \text { (Victoria) }\end{array}$ & [7] \\
\hline White grape Sonaka & Visual assessment & $\begin{array}{l}\text { RGB } \\
\text { HSV }\end{array}$ & 4000 & $\begin{array}{c}\text { Convolutional NN (CNN), } \\
\text { support vector machine (SVM) }\end{array}$ & $\begin{array}{c}\text { Classification rates: } 79 \%(\mathrm{CNN}) \\
69 \%(\mathrm{SVM})\end{array}$ & [8] \\
\hline Cabernet Sauvignon & Visual assessment & RGB & 13 & Neural network (NN) & Average error: $5.36 \%$ & [9] \\
\hline $\begin{array}{l}\text { Syrah, Cabernet } \\
\text { Sauvignon }\end{array}$ & $\begin{array}{l}\text { TSS, flavonoid, } \\
\text { anthocyanin }\end{array}$ & RGB & 1008 & Convolutional neural networks & $\begin{array}{c}\text { Classification rates: } 93.41 \% \text { (Syrah), } \\
72.66 \% \text { (Cabernet) }\end{array}$ & [10] \\
\hline
\end{tabular}




\section{Conclusions}

Nowadays, fruits are still harvested manually by fruit pickers, based on subjective criteria and extensive sampling, followed by chemical analyses. Maturity is critical for the storage life of harvested fruits, and the quality of table grapes and produced wines. The degree of maturity defines the way grapes are further processed. Machine vision algorithms are employed for grape ripeness estimation, as a non-destructive, labor-saving, cost-effective, and eco-friendly alternative. This work explores the possible applications of machine vision technology in grape ripeness estimation, and discusses the limitations and challenges hindering their successful adoption for sustainable agricultural automation.

Author Contributions: Conceptualization, G.A.P. and E.V.; methodology, E.V.; investigation, E.V. and C.B.; resources, E.V. and C.B.; writing-original draft preparation, E.V. and C.B.; writing-review and editing, E.V, G.A.P., T.P. and V.G.K.; visualization, C.B.; supervision, G.A.P.; project administration, G.A.P., T.P. and V.G.K.; funding acquisition, V.G.K. and G.A.P. All authors have read and agreed to the published version of the manuscript.

Funding: This research has been co-financed by the European Regional Development Fund of the European Union and Greek national funds through the Operational Program Competitiveness, Entrepreneurship and Innovation, under the call RESEARCH-CREATE-INNOVATE (project code: T1EDK-00300).

Institutional Review Board Statement: Not applicable.

Informed Consent Statement: Not applicable.

Data Availability Statement: Not applicable.

Conflicts of Interest: The authors declare no conflict of interest.

\section{References}

1. Gomes, V.; Fernandes, A.; Martins-Lopes, P.; Pereira, L.; Mendes Faia, A.; Melo-Pinto, P. Characterization of Neural Network Generalization in the Determination of PH and Anthocyanin Content of Wine Grape in New Vintages and Varieties. Food Chem. 2017, 218, 40-46. [CrossRef] [PubMed]

2. Iatrou, G.; Mourelatos, S.; Gewehr, S.; Kalaitzopoulou, S.; Iatrou, M.; Zartaloudis, Z. Using Multispectral Imaging to Improve Berry Harvest for Wine Making Grapes. Ciência e Técnica Vitivinícola 2017, 32, 33-41. [CrossRef]

3. Baca-Bocanegra, B.; Nogales-Bueno, J.; Heredia, F.; Hernández-Hierro, J. Estimation of Total Phenols, Flavanols and Extractability of Phenolic Compounds in Grape Seeds Using Vibrational Spectroscopy and Chemometric Tools. Sensors 2018, 18, 2426. [CrossRef] [PubMed]

4. Hernández-Hierro, J.M.; Nogales-Bueno, J.; Rodríguez-Pulido, F.J.; Heredia, F.J. Feasibility Study on the Use of Near-Infrared Hyperspectral Imaging for the Screening of Anthocyanins in Intact Grapes during Ripening. J. Agric. Food Chem. 2013, 61, 9804-9809. [CrossRef] [PubMed]

5. Xia, Z.; Wu, D.; Nie, P.; He, Y. Non-Invasive Measurement of Soluble Solid Content and PH in Kyoho Grapes Using a Computer Vision Technique. Anal. Methods 2016, 8, 3242-3248. [CrossRef]

6. Hernández, S.; Morales, L.; Urrutia, A. Unsupervised Learning for Ripeness Estimation from Grape Seeds Images. Int. J. Smart Sens. Intell. Syst. 2017, 10, 594-612. [CrossRef]

7. Cavallo, D.P.; Cefola, M.; Pace, B.; Logrieco, A.F.; Attolico, G. Non-Destructive and Contactless Quality Evaluation of Table Grapes by a Computer Vision System. Comput. Electron. Agric. 2019, 156, 558-564. [CrossRef]

8. Kangune, K.; Kulkarni, V.; Kosamkar, P. Grapes Ripeness Estimation Using Convolutional Neural Network and Support Vector Machine. In Proceedings of the 2019 Global Conference for Advancement in Technology, GCAT 2019, Bangalore, India, 12-18 October 2019. [CrossRef]

9. Kaburlasos, V.G.; Vrochidou, E.; Lytridis, C.; Papakostas, G.A.; Pachidis, T.; Manios, M.; Mamalis, S.; Merou, T.; Koundouras, S.; Theocharis, S.; et al. Toward Big Data Manipulation for Grape Harvest Time Prediction by Intervals' Numbers Techniques. In Proceedings of the 2020 International Joint Conference on Neural Networks (IJCNN), Glasgow, UK, 19-24 July 2020; pp. 1-6. [CrossRef]

10. Ramos, R.P.; Gomes, J.S.; Prates, R.M.; Simas Filho, E.F.; Teruel, B.J.; Dos Santos Costa, D. Non-Invasive Setup for Grape Maturation Classification Using Deep Learning. J. Sci. Food Agric. 2021, 101, 2042-2051. [CrossRef] [PubMed] 